Nat. Hazards Earth Syst. Sci., 10, 565-569, 2010

www.nat-hazards-earth-syst-sci.net/10/565/2010/

(C) Author(s) 2010. This work is distributed under

the Creative Commons Attribution 3.0 License.

\title{
Comparison of seasonal variability in European domestic radon measurements
}

\author{
C. J. Groves-Kirkby, A. R. Denman, P. S. Phillips, R. G. M. Crockett, and J. M. Sinclair \\ School of Science and Technology, University of Northampton, Northampton NN2 6JD, UK \\ Received: 21 October 2009 - Revised: 22 February 2010 - Accepted: 8 March 2010 - Published: 26 March 2010
}

\begin{abstract}
Analysis of published data characterising seasonal variability of domestic radon concentrations in Europe and elsewhere shows significant variability between different countries and between regions where regional data is available. Comparison is facilitated by application of the Gini Coefficient methodology to reported seasonal variation data. Overall, radon-rich sedimentary strata, particularly high-porosity limestones, exhibit high seasonal variation, while radon-rich igneous lithologies demonstrate relatively constant, but somewhat higher, radon concentrations. Highvariability regions include the Pennines and South Downs in England, Languedoc and Brittany in France, and especially Switzerland. Low-variability high-radon regions include the granite-rich Cornwall/Devon peninsula in England, and Auvergne and Ardennes in France, all components of the Devonian-Carboniferous Hercynian belt.
\end{abstract}

\section{Introduction}

In temperate zones, domestic radon concentration levels are generally seasonally dependent, the measured level reflecting convolution of two time-dependent functions, namely the source soil-gas radon concentration itself and the pressuredifference between interior and exterior environment, the principal force driving radon into the building from the soil. While meteorological influence can be regarded as relatively uniform on a European scale, being defined largely by the influence of North-Atlantic weather systems, soil-gas radon, essentially geologically dependent, is generally more variable. The extent of seasonal variability of domestic radon

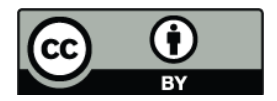

Correspondence to: C. J. Groves-Kirkby (chris.groves-kirkby@northampton.ac.uk) concentration may therefore be expected to vary with location, and this is found to be the case (Groves-Kirkby et al., 2009).

To compensate for domestic radon variability when assessing long-term health risks, individual short-term measurement results are conventionally converted to equivalent mean annual levels by use of a multiplier Seasonal Correction Factor (SCF) (Pinel et al., 1995), typically derived from measurements of a large number of homes, reflecting the period of the year during which the measurement took place. Following concern as to the universal applicability of a single SCF set, studies in the United Kingdom (UK) (Pinel et al., 1995; UKCC, 2002) and France (Baysson et al., 2003) have reported location-specific SCF sets for different regions of each country. UK SCFs differ significantly from those applicable in Continental Europe and elsewhere in both amplitude and phase, supporting the thesis (Denman et al., 2007) that seasonal variability in indoor radon concentration cannot realistically be compensated for by a single national or international SCF correction policy.

\section{Method}

Published data characterizing seasonal variability of national domestic radon concentrations was collated and analyzed, in order to identify correlations between published datasets and local geographic/geological conditions. This data included regional SCF figures from the UK (Pinel et al., 1995; UKCC, 2002) and from France (Baysson et al., 2003), together with nationally-consolidated results from a number of other countries in Europe and elsewhere in the Northern Hemisphere.

While processing this data, the authors became aware of the use of the Lorenz Curve (Lorenz, 1905) and Gini Coefficient, $G$, (Gini, 1913) as tools for analysing and quantifying

Published by Copernicus Publications on behalf of the European Geosciences Union. 


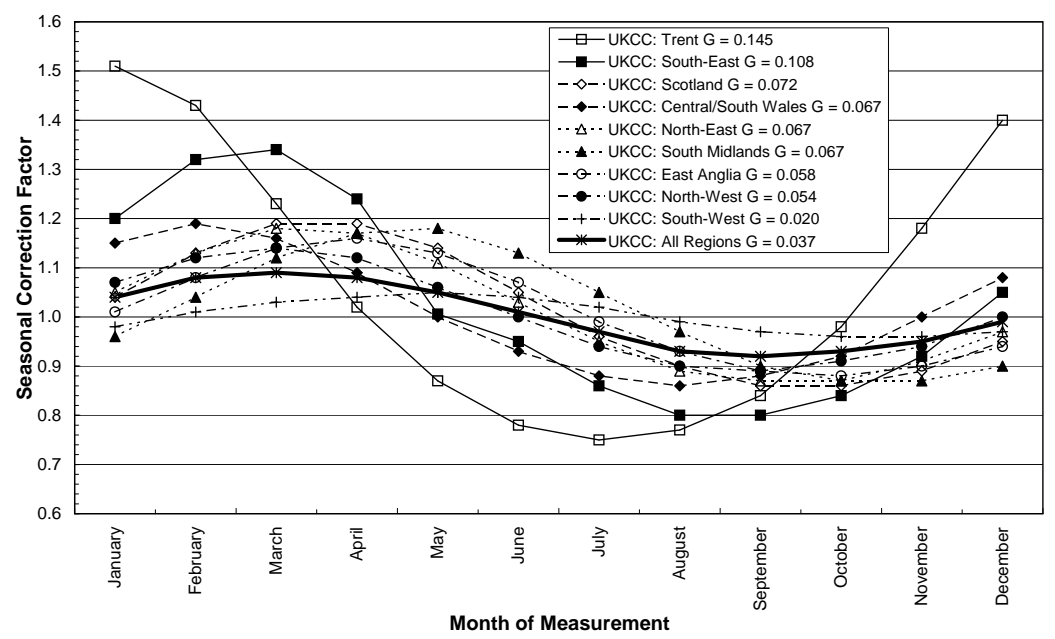

Fig. 1. Regional variation of Seasonal Correction Factors for 6-month exposures in Great Britain (UKCC, 2002) with derived values of the Gini coefficient.

data representing non-uniform socio-economic distributions, and identified an analysis of seasonal data (Lee, 1996) which interpreted the Gini Coefficient as a probability function characterising temporal clustering. Following this approach, we recently reported single-parameter characterisation of seasonal radon variability via the Lorenz Curve and the Gini Coefficient (Groves-Kirkby et al., 2009). Gini coefficients were derived from each SCF data set, using the following methodology:

1. for each month for which either SCF or mean radon concentration data are available, the fraction of the total annual exposure experienced is calculated, taking account of the variable month length of the Gregorian calendar;

2. months are ranked by increasing exposure fraction;

3. using the ranked data, the Gini Coefficient, $G$, is calculated using the formula given by Brown (1994):

$G=\left|1-\sum_{k-1}^{n}\left(X_{k-1}\right)\left(Y_{k}-Y_{k-1}\right)\right|$

where:

$X_{k}$ is the cumulative fractional elapsed time for $k=0, \ldots n$, with $X_{0}=0, X_{1}=1$;

$Y_{k}$ is the cumulative fractional radon exposure for $k=0, \ldots n$, with $Y_{0}=0, Y_{1}=1$.

In the context of radon concentration seasonality, a Gini Coefficient of 0 indicates that radon concentration levels are uniform throughout the year. A coefficient of 1 indicates that all of the exposure occurs within one measuring period (e.g. 1 month for 1-month measurements). It does not indicate during which measuring period that exposure occurs. Values for radon seasonality are in the range 0.05 to 0.3 , where higher values indicate increased seasonal variability.

\section{Geographic/geological analysis}

\subsection{United Kingdom}

The UK Childhood Cancer collaboration (UKCC, 2002) investigated domestic radon gas as a carcinogen, reporting monthly SCFs for geographical regions within Britain and for the island as a whole. Figure 1 presents the seasonal variability of the regional SCFs graphically, while Table 1 summarises Gini Coefficients from this and other reported UK datasets. While all regions show seasonal variability, significant inter-regional differences also exist. Gini Coefficients range from 0.02 in South-West England to 0.145 in the Trent Region, while a wide region, ranging from East Anglia to Wales and extending North to Scotland, shows values of $G$ in the range $0.05-0.07$. Finally, national-average SCFs reported by UKCC (2002) and the UK Health Protection Agency (HPA) (Wrixon et al., 1988; Woods et al., 2000) give values for $G$ of 0.037 and 0.038 respectively, showing very good agreement considering that these were derived from independent experimental studies.

In ascribing origins for SCF variability, the geography of the extreme values, 0.02 in the granite-rich south-west peninsula and 0.145 in the limestone-based south-Pennines, both known high-radon areas, offers insight. Devon and Cornwall both form part of the Devonian-Carboniferous Hercynian orogenic belt (Ziegler, 1990), which extends from the Iberian peninsula through South-West Ireland and South-West England to France and Germany. The dense uranium-rich granite batholith in Devon and Cornwall provides a constant radon 
Table 1. Seasonal variation of domestic radon concentrations in the UK.

\begin{tabular}{llccc}
\hline Region & Source & Dataset & Gini Coefficient & $\begin{array}{c}\text { (Max-Min)/ } \\
\text { Mean }\end{array}$ \\
\hline South-West & UKCC, 2002 & 731 & 0.020 & 0.090 \\
North-West & UKCC, 2002 & 772 & 0.054 & 0.248 \\
East Anglia & UKCC, 2002 & 467 & 0.058 & 0.277 \\
Central/South Wales & UKCC, 2002 & 538 & 0.067 & 0.326 \\
North-East & UKCC, 2002 & 745 & 0.067 & 0.307 \\
South Midlands & UKCC, 2002 & 573 & 0.067 & 0.306 \\
Scotland) & UKCC, 2002 & 860 & 0.072 & 0.326 \\
South-East & UKCC, 2002 & 429 & 0.108 & 0.526 \\
Trent & UKCC, 2002 & 563 & 0.145 & 0.715 \\
All Regions & UKCC, 2002 & 5678 & 0.037 & 0.169 \\
UK - NRPB & Wrixon et al., 1988 & & 0.195 & 1.204 \\
UK & Woods et al., 2000 & 2093 & 0.194 & 1.184 \\
South-West & Pinel et al., 1995 & & 0.113 & 0.541 \\
\hline
\end{tabular}

flux, its location close to the surface and strongly fissured nature suggesting a relatively constant emanation rate throughout the year. In contrast, the geology in the Trent region comprises porous Carboniferous limestone in the Pennines and Jurassic bedrock overlain by permeable soils in the Trent valley and Lincolnshire Wolds. This is a combination where the influence of climatic effects, particularly air convection within the ground (Arvela et al., 1988), can be expected to be more significant (Eaton and Scott, 1984). The observed Gini coefficient, 0.145, supports this expectation. Intermediate, with $G=0.108$, is South-East England, underlain by Cretaceous rocks with relatively low radon potential.

\subsection{France}

Baysson et al. (2003) studied radon seasonality in France using data from the whole country and from a case-control study in five principal regions. Regional variability was comparable with that within the UK, and Gini coefficient analysis is summarised in Table 2. Auvergne and Ardennes, with $G=0.03$, are also parts of the Hercynian belt, with comparable lithology to Devon and Cornwall and, particularly in Auvergne, with igneous rocks close to the surface. The low values of $G$ found in these regions are therefore not unexpected on the basis of the previous argument. The Languedoc and Bretagne regions of France, also underlain by igneous rocks, exhibit more extensive and diverse superficial sedimentary geology, suggestive of the observed relatively high values of $G, 0.095$, with Languedoc influenced by the Pyrenees massif. The overall national Gini Coefficient, $G=0.050$, is slightly higher than that of UK.

\subsection{Other continental Europe locations}

Table 3 summarises seasonal radon variability reported from other European countries. With $G=0.223$, Switzerland
Table 2. Seasonal variation of domestic radon concentrations in France (Baysson et al., 2003).

\begin{tabular}{lccc}
\hline Region & Dataset & Gini Coefficient & $\begin{array}{c}(\text { Max-Min)/ } \\
\text { Mean }\end{array}$ \\
\hline Auvergne & 315 & 0.030 & 0.130 \\
Ardennes & 329 & 0.033 & 0.159 \\
Limousin & 587 & 0.043 & 0.199 \\
Languedoc & 294 & 0.095 & 0.448 \\
Bretagne & 656 & 0.096 & 0.449 \\
All Regions & 11186 & 0.037 & 0.169 \\
\hline
\end{tabular}

(Tapia et al., 2006), at the centre of the extensive ongoing Alpine orogeny and with much of the densely inhabited areas overlain with light, porous, recent sediments, exhibits the greatest level of European seasonality yet encountered. Comparable variability ( $G=0.21$ ) is found in a single study from Italy (Azimi, 1996), likewise a region of relatively recent geological activity still prone to seismic events. In contrast, the Gini coefficients of 0.13 and 0.14 from Poland (Karpinska et al., 2004) and Ireland (Madden et al., 1994) respectively are comparable to figures from the English Midlands, reflecting the relatively stable sedimentary geology found in both areas.

\subsection{North America/Asia/Australasia}

USA seasonality data are limited, with values for $G$ ranging from 0.065 in North Dakota (Momčilovič et al., 2007) to 0.223 in Minnesota (Steck et al., 2004) (Table 4). Outside the USA, $G=0.227$ is found in the Winnipeg, Manitoba, Canada (Krewski et al., 2005), while the highest value so far identified worldwide, $G=0.265$, is found in Amritsar, India (Singh et al., 2008). Winnipeg is situated on the recent deep 
Table 3. Seasonal variation of domestic radon concentrations in European countries.

\begin{tabular}{llccc}
\hline Country & Source & Dataset & Gini Coefficient & $\begin{array}{c}\text { (Max-Min)/ } \\
\text { Mean }\end{array}$ \\
\hline Poland & Karpinska et al., 2004 & 10 & 0.132 & 0.704 \\
Ireland & Madden et al., 1994 & & 0.142 & 0.759 \\
Austria & Bossew and Lettner, 2007 & 7280 & 0.167 & 1.030 \\
Italy (Roma) & Azimi, 1996 & 120 & 0.214 & 1.328 \\
Switzerland & Tapia et al., 2006 & & 0.223 & 1.525 \\
\hline
\end{tabular}

Table 4. Seasonal variation of domestic radon concentrations in Northern Hemisphere countries outside Europe.

\begin{tabular}{llccc}
\hline Country & Source & Dataset & Gini Coefficient & $\begin{array}{c}\text { Max-Min)/ } \\
\text { Mean }\end{array}$ \\
\hline USA (ND) & Momčilovič and Lykken, 2007 & 2492 & 0.065 & 0.373 \\
USA (MN) & Steck et al., 2004 & 1 & 0.223 & 1.486 \\
Canada (Winnipeg) & Krewski et al., 2005 & & 0.227 & 1.113 \\
India (Amritsar) & Singh et al., 2008 & 1 & 0.265 & 1.382 \\
\hline
\end{tabular}

clay bed of pre-historic glacial Lake Agassiz (Upham, 1895), while Amritsar, on the Punjab plain, is located on granite bedrock overlain with several hundred metres of quaternary limestones and dolomites (Kochar, 2004). Since glacial sediments are known to be susceptible to enhanced radon permeability (Arvela et al., 1988), and since radon mobility in permeable strata is known to be sensitive to climatic influences (Arvela et al., 1994), the enhanced seasonal variability in these strata, as confirmed by the high values for $G$, is not surprising.

\section{Conclusions}

Analysis of published SCF data shows significant differences in seasonal variability between different countries and different regions within those countries. On the basis of the limited available data, it is possible to draw tentative conclusions as to the relationship between underlying geology and seasonable radon variability. Radon-rich sedimentary strata, particularly high porosity limestones etc., exhibit high seasonal variation, while radon rich igneous geologies demonstrate relatively constant, but somewhat higher, radon concentration levels. Examples of the former can be found in the Pennines and Trent valley in England, and in Languedoc and Bretagne in France, where values of $G$ range from 0.07 to 0.14 . Low-variability high-radon regions include the granite-rich Cornwall/Devon peninsula in England, and Auvergne and the Ardennes in France, where values of $G$ are significantly lower (0.02-0.03). The dense uranium-rich granite dominating Devon and Cornwall is strongly fissured and located close to the surface, suggesting a high, yet rel- atively constant, emanation rate throughout the year. Locally, the Devon/Cornwall granites are subject to greisenisation. This post-magmatic process, associated with highsilica granites, leads to feldspar and mica decomposition (and thence to changes in permeability), polymetallic mineral formation, localised texture and uranium content variations. Although these all have the potential to introduce elements of geographic variability, this spatial detail is inevitably lost when data collected across an extended geographical region is consolidated, as in the present case. Moderate-variability high-radon regions, including the deep sedimentary Jurassic and Cretaceous of central and south-eastern England, Ireland and the plains of eastern Poland, all show intermediate values of $G$.

The Gini Coefficient would appear to provide a convenient single index of seasonal radon variability. However, the loss of the time dimension might empirically be thought to be problematic, and have the potential to hide important features of such a variation, such as a sharp single peak in radon levels. However, as a result of the seasonal radon variation being essentially sinusoidal, the Gini Coefficient tracks the difference between minimum and maximum radon levels with a high degree of correlation $\left(R^{2}>0.9\right)$, as shown in the final column of each table, thus supporting its value in this application.

Acknowledgements. The authors are grateful for constructive comments from both the editor and the referees during the preparation of this paper.

Edited by: G. Gillmore

Reviewed by: two anonymous referees 


\section{References}

Arvela, H., Voutilainen, A., Honkamaa, T., and Rosenberg, A.: High indoor radon variations and the thermal behaviour of eskers, Health Phys., 67, 254-260, 1994.

Arvela, H., Voutilainen, A., Mäkeläinen, I., Castren, O., and Winqvist, K.: Comparison of predicted and measured variations of indoor radon concentration, Radiat. Prot. Dosim., 24, 231-235, 1988.

Azimi, D.: Prediction of seasonal radon concentration from weekly screening measurements, Indoor Built. Environ., 5, 181-183, 1996.

Baysson, H., Billon, S., Laurier, D., Rogel, A., and Tirmarche, M.: Seasonal correction factors for estimating radon exposures in dwellings in France, Radiat. Prot. Dosim., 104, 245-252, 2003.

Bossew, P. and Lettner, H.: Investigations on indoor radon in Austria, part 1: seasonality of indoor radon concentration, J. Environ. Radioactiv., 98, 329-345, 2007.

Brown, M.: Using Gini-style indexes to evaluate the spatial pattern of health practitioners: theoretical considerations and an application based on Alberta data, Soc. Sci. Medicine, 38, 1243-1256, 1994.

Denman, A. R., Crockett, R. G. M., Groves-Kirkby, C. J., Phillips, P. S., Gillmore, G. K., and Woolridge, A. C.: The value of seasonal correction factors in assessing the health risk from domestic radon - a case study in Northamptonshire, UK, Environ. Int., 33, 34-44, 2007.

Eaton, R. S. and Scott, A. G.: Understanding radon transport into houses, Radiat. Prot. Dosim., 7, 251-253, 1984.

Gini, C.: Memorie di metodologia statistica, Variabilita e Concentrazione, J. Roy. Statistic. Soc., 76, 326-327, 1913.

Groves-Kirkby, C. J., Denman, A. R., and Phillips, P. S.: Lorenz Curve and Gini Coefficient: novel tools for analysing seasonal variation of environmental radon gas, J. Environ. Manage., 90, 2480-2487, 2009.

Karpinska, M., Mnich, Z., and Kapala, J.: Seasonal changes in radon concentrations in buildings in the region of north-eastern Poland, J. Environ. Radioactiv., 77, 101-109, 2004.

Kochar, N.: Geological features and health problems, The Tribune (India) 8 January 2004, available online at: www.tribuneindia. com/2004/20040108/science.htm (last access: March 2010), 2004.
Krewski, D., Mallick, R., Zielinski, J., and Létourneau, E.: Modeling seasonal variation in indoor radon concentrations, J. Expo. Anal. Env. Epid., 15, 234-243, 2005.

Lee, W.-C.: Analysis of seasonal data using the Lorenz Curve and the associated Gini index, Int. J. Epidemiol., 25, 426-434, 1996.

Lorenz, M.: Methods of measuring the concentration of wealth, Am. Stat. Assoc., 9, 209-219, 1905.

Madden, J., Duffy, J., Mackin, G., Colgan, P., and McGarry, A.: Radon in dwellings in selected areas of Ireland, RPII94/3, RPII, Dublin, 1994.

Momčilovič, B. and Lykken, G. I.: Seasonality of ${ }^{214}$ Bi activity in the human body and of ${ }^{222} \mathrm{Rn}$ concentration in home ambient air, Health Phys., 92, 484-487, 2007.

Pinel, J., Fearn, T., Darby, S. C., and Miles, J. C. H.: Seasonal correction factors for indoor radon measurements in the United Kingdom, Radiat. Prot. Dosim., 58, 127-132, 1995.

Singh, M., Singh, K., Singh, S., and Papp, Z.: Variation of indoor radon progeny concentration and its role in dose assessment, J. Environ. Radioactiv., 99, 539-545, 2008.

Steck, D. J., Capistrant, J. A., Dumm, J. P., and Patton, E. S.: Indoor radon exposure uncertainties caused by temporal variation, 11th Int. Congr. IRPA, Madrid, 23-28 May, 2004.

Tapia, R., Kanevski, M., Maignan, M., and Gruson, M.: Comprehensive multivariate analysis of indoor radon data in Switzerland, 8th International Workshop "Geological aspects of radon risk mapping”, Prague, 26-30 September, 2006.

UKCC Investigators: The United Kingdom Childhood Cancer Study: objectives, materials and methods, Brit. J. Cancer, 82, 1073-1102, 2002.

Upham, W.: The Glacial Lake Agassiz, Monographs of the US Geological Survey, Government Printing Office, Washington DC, 1895 .

Woods, M. J., Dean, J. C. J., Jerome, S. M., and Modna, D. K.: Review of rapid methods for assessing radon levels in domestic premises, DETR/RAS/99.012, DETR, London, 2000.

Wrixon, A. D., Green, B. M. R., Lomas, P. R., Miles, J. C. H., Cliff, K. D., Francis, E. A., Driscoll, C. M. H., James, A. C., and O'Riordan, M. C.: Natural radiation exposure in UK dwellings, NRPB-R190, NRPB, Chilton, 1988.

Ziegler, P. A.: Geological Atlas of Western and Central Europe, Shell Internationale Petroleum Maatschappij BV (2nd Ed.), The Hague, ISBN 90-6644-125-9, 1990. 